\title{
Evaluation of the Behavior of Some Genotypes of Salix sp. in the Conditions of Sandy Soils
} \author{
Florin PANITA ${ }^{1}$ \\ ${ }^{1}$ Faculty of Agronomy, University of Craiova, Libertatii Street, no 19, 200583, Romania, \\ ${ }^{2}$ Faculty of Horticulture, University of Craiova, A.I. Cuza Street, no 13, Romania, \\ *corresponding author, e-mail: paula.iancu76@gmail.com
}

Marin SOARE ${ }^{1}$, Paula IANCU ${ }^{*}$, Elena BONCIU ${ }^{1}$, Ion NICOLAE², Luminita BUSE DRAGOMIR ${ }^{2}$, Ovidiu

Bulletin USAMV series Agriculture 75(1)/2018

Print ISSN 1843-5246; Electronic ISSN 1843-5386

DOI 10.15835/buasvmcn-agr: 003017

\begin{abstract}
The aim of this study was to make a comparative analyse of nine willow genotypes (seven Romanian and two Swedish clones) in order to test them for short rotation coppice. Researches have been carried out in the sandy soils from Southern Romania, over a period of two years of vegetation. There were made determinations as concern plants growth and development and were referring to survival rate, stem height, number of shoots/plant and stem diameter at the base. Hydric stress is one of the main factors of limiting plant growth on this type of soil and the experimented willow genotypes have reacted differently. The obtained results have shown the fact that the largest vegetative growth was recorded in Pesred and Inger genotypes. It also emphasizes with good results in terms of the quantity of biomass RO 1077, Fragisal and Robisal genotypes. Based on the obtained results it can appreciate that Salix sp. represents a solution of utilize the sandy soils which have low fertile and obtaining considerable amounts of biomass, in the conditions of ensuring of water and nutritive resources.
\end{abstract}

Keywords: short rotation crops (SRC), sandy soil, quantitative characteristics

\section{Introduction}

The current energy resource crisis is looking for a range of non-food crops that can be grown on less fertile land to be used as renewable energy sources. Short rotation crops (SRC) energy sludge is a viable alternative for this purpose due to its capacity to use marginal and non-agricultural land.

In this way it was taken into study the behaviour of a wide range of genotypes of Salix species cultivated on a sandy soil, poorly fertile, in order to identify the ones that are suitable to be cultivated under this conditions with occasional periods of water shortage.

Fast-growing plants of short rotation forests are able to produce high yields during shortperiods. Since the 1980s, willows have become recognized as a biomass crop (Karp, 2015). Energy willow is one of the plants cultivated for superior calorific properties, therefore pellets made of this burning better than wood. Apart from the exploitation of biomass for energy, this crop it is appropriate for forestry wind brakes, due to specific properties: minimal requirements regarding soil quality, rapid growth, forming dense bushes, etc.

Willow crops for biomass determine the increase of habitat diversity being experimented in improper agricultural areas for annual plants and not in forestry exploitations surfaces. These crops can exploits lands in the slope fixing the soil and improving his quality and also can have bioremediation role of polluted soils extracting the ions which are in excess and can be utilized for productive circle of some powerful polluted soils such as tailings dumps, saline soils, eroded, sandy soils, etc.

The materials obtained from willow can be further processed into various forms of solid fuels. In this case, the mechanical properties are important, i.e. volume weight and mechanical solidity. These parameters depend on used 
material, its structure, water content and compacting pressure (Weger et al., 2016)

In Romania, willow short rotation coppice has been developed from 2005, exclusively on agricultural, non-forest land, about 800 ha of willow and Inger is the most cultivated commercial Swedish clone in Romania (Hernea et al., 2015), but a few experimental trials clone have been made in order to test the capacity of willow clones to adapt in different sites condition.

Advantages of using SRC willow for biomass production include fast growth and high biomass production, ability to re-sprout after multiple harvests, ease of vegetative propagation from dormant woody cuttings, low investments after its establishment, ability to recycle wastewater (Dimitriou et al., 2009). The willow crop in SRC is considered a sustainable source of biomass with a positive greenhouse gas (GHG) due to their potential to fix carbon (C) in soil. Willow short rotation coppice is an option for raising demand for bioenergy. But willows are also important for phytoremediation or salicylic acid content (Hernea et al., 2016).

Water retention ability represents a physiology indicator related to water use efficiency. It was found that diurnal dynamics of transpiration showed one peak (typically at midday) for all clones (Rodzkin et al., 2015). Hydric stress is one of the most important factors responsible for limiting plant growth and productivity. The longterm prognosis of global climate change includes very frequent drought episodes.

Many of the degraded lands that could be cultivated with energy willow are subject to desertification phenomenon due to climate change and the cutting of forest protection curtains. Water deficiency in the soil becomes critical and it is therefore necessary to select tolerant genotypes to longer periods of water stress.

Because of the general susceptibility of willows to drought stress, breeding of Salix hybrids for biomass plantations in Southern Europe may involve selection challenge for occasional periods of water shortage. Breeding and selection strategies in Salix should be different depending on the kind of drought tolerance that is relevant (Bonosi et al., 2010).

Some authors reported that willow genotypes are able to improve drought resistance (acclimate) after long-term moderate drought (Wikberg et al., 2007).

\section{Materials and methods}

The study was conducted on an assortment of genotypes of Salix spp., in the climatic conditions from Southern Romania, on the sandy soil of Tamburesti village, Dolj County, with the GPS

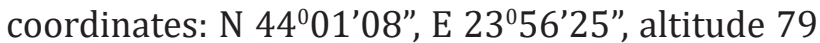
$\mathrm{m}$. The climate is continental, the mean annual temperature is $11.3^{\circ} \mathrm{C}$ and the annual precipitation sum is between $368-580 \mathrm{~mm}$, with $152-420 \mathrm{~mm}$ in the growing period, based on the observation made to Bechet Meteorological Centre.

The experimental trail was established in 2015 starting with field preparation (ploughing and harrowing) on a sandy soil. The experience was planted manually using $20 \mathrm{~cm}$ long cuttings, in double rows at a spacing $150 \times 75 \mathrm{~cm}$ and $70 \mathrm{~cm}$ between cuttings, realizing a designed according to randomized complete block split-block with three replications. Conventional crop technology of energy willow was applied. Weeding control was performed using herbicides and mechanical tilling. Observations were made in order to establish the survival rate and also biometrical parameters.

The evaluation of quantitative characteristics was made by measurement of diameter $(0.01 \mathrm{~mm}$ precision) and the maximum height of every plant (1 $\mathrm{cm}$ precision). The plants were evaluated in November. For 50 willow plants were registered the number of shoots per stool, the maximum height of the shoots and the diameter of the highest shoot per stool.

The biological material was represented by seven Romanian genotypes and two foreign genotypes that can be suitable for cropping in the conditions in this area, which are: R0892, R01077, R01082 (provided by National Institute for Research and Development in Forestry "Marin Drăcea" - NIRDF), Cozia, Fragisal, Pesred, Robisal (from Fruit Growing Research and Development Unit of Vâlcea (SCDP Vâlcea) and CHPs Govora), Inger and Tordis (Swedish clones from a Holland Alma Kft Hungarian Nursery).

The genotype was the only analysed factor. Collected data were statistically calculated with ANOVA using the Fisher's technique. The least significant difference (LSD) test at 0.05 was used to compare means. 


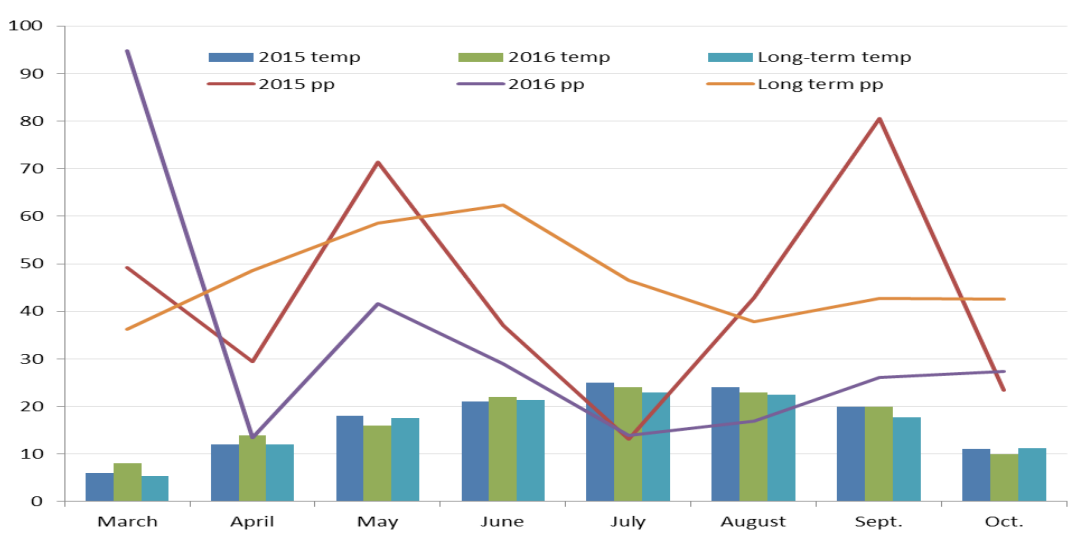

Figure 1. Climatic data from experimental field from Tamburesti, Dolj County, Romania

Table 1. Survival rate for experimented genotypes (\%)

\begin{tabular}{|c|c|c|c|c|c|c|c|c|c|c|c|}
\hline $\begin{array}{c}\text { Genotype/ } \\
\text { Date }\end{array}$ & $\begin{array}{l}\text { ๙ } \\
\infty \\
\circ \\
\simeq 1\end{array}$ & 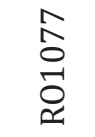 & 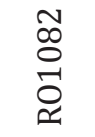 & ن & 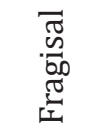 & 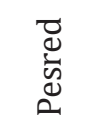 & 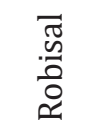 & 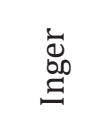 & 包 & St. dev. & $\mathrm{s} \%$ \\
\hline May, 2015 & 92.34 & 90.41 & 91.42 & 84.53 & 90.33 & 92.72 & 91.05 & 98.65 & 91.12 & 3.82 & 12.14 \\
\hline Nov. 2015 & 78.32 & 70.24 & 71.61 & 66.70 & 72.43 & 84.41 & 78.32 & 84.46 & 60.08 & 4.22 & 15.22 \\
\hline
\end{tabular}

Physiology research consisted in analysing chlorophyll content which was determined using Minolta SPAD 502 portable clorophilmeter. The total content of water and dry matter was determined by gravimetric methods, using the oven (drying of plant material at a temperature of $\left.100-105^{\circ} \mathrm{C}\right)$.

Climatic conditions from South Romania are characterized through high temperatures in July and August months and the quantity of rainfall is low, which strongly influenced the growth of plants (Fig. 1). At the end of vegetation period, at the beginning of November it was made determinations to the main morphological characters such as: plants height, number of stems/plant, stem diameter and dry matter content of biomass, on each variant.

\section{Results and discussions}

In the present study, it was analysed the interaction between genotype and enviroment, in order to understand the way how genotypes reacts on the specific enviromental conditions from the sandy soils.

Climatic conditions from Southern Oltenia are relatively favourable only in the first half of vegetation period of the year (Fig. 1). After this period, the temperature rises and drought occurs, which cumulates with poor water retention capacity by the sand, thus makes plants to be exposed to hydric and heat stress, affecting plants growth and development, the survival rate being an essential element for a successful plantation of willow crop and for good results and has to be over $90 \%$.

On this experiment, in May 2015, the survival rate depended on genotype; high values of this indicator registered Cozia (84.53\%) and Inger (98.65\%) in the first part of the vegetation period (Table1). All survival rate decreased in November 2015 - 60.08\% (Tordis) and (84.46\%), probably because of the hot and dry summer (high temperature and no rainfall). The plants which that did not survive were replaced with new cuttings in the spring next year.

Analysing the registered data as concern morphology of growth, it can noticed a high variability of the experimented genotypes. Plants height recorded higher amplitude (Fig. 2), maximum values registering Pesred genotype (180 $\mathrm{cm}$ ) (a- significant positive difference comparative to R01082, Cozia, Fragisal, Robisal and Tordis genotypes) while minimum value was observed at Fragisal genotype $(98 \mathrm{~cm})$ (c- significant negative difference comparative to RO 1077, RO 1082, Pesred, Robisal and Inger genotypes). With higher values can be mentioned also on Inger (178.6 $\mathrm{cm})$ and RO $1077(171.2 \mathrm{~cm})$ genotypes. Average 


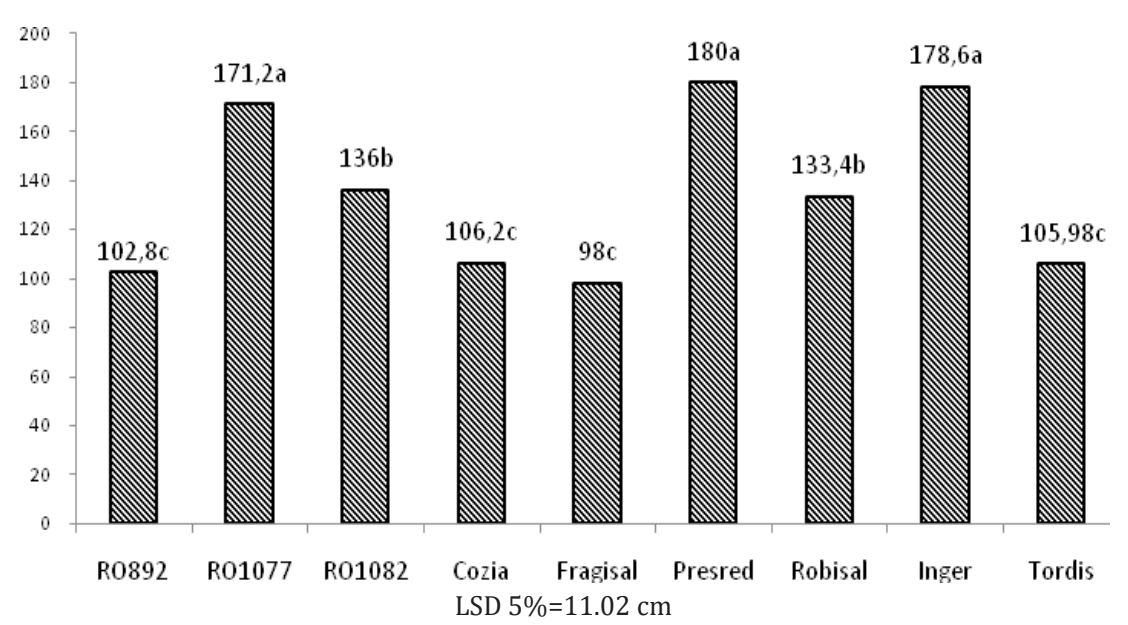

Figure 2. The average length of annual growth $(\mathrm{cm})$

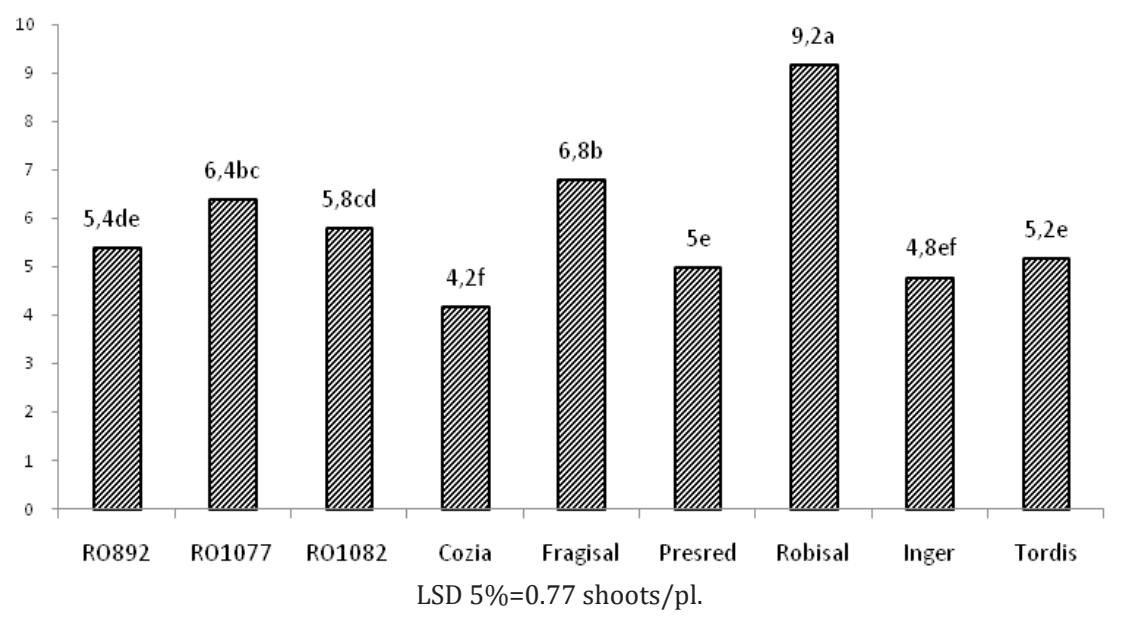

Figure 3. No. of shoots at studied Salix genotypes

Table 2. Diameter (mm) at the bottom of the highest shoot per stool of willow genotypes measured in November 2015

\begin{tabular}{ccccc}
\hline \multirow{2}{*}{ Crt. no } & \multirow{2}{*}{ Clone } & \multicolumn{3}{c}{ Base diameter (mm) } \\
\cline { 3 - 5 } & & Average & St. dev. & $\mathrm{s} \%$ \\
\hline 1 & R0892 & $7.41^{\mathrm{ab}}$ & 2.53 & 23.21 \\
\hline 2 & R01077 & $8.21^{\mathrm{a}}$ & 2.64 & 20.35 \\
\hline 3 & R01082 & $6.22^{\mathrm{abc}}$ & 1.17 & 12.21 \\
\hline 4 & Cozia & $5.14^{\mathrm{bcd}}$ & 0.73 & 10.44 \\
\hline 5 & Fragisal & $7.51^{\mathrm{ab}}$ & 1.34 & 16.81 \\
\hline 6 & Pesred & $8.19^{\mathrm{a}}$ & 3.16 & 28.85 \\
\hline 7 & Robisal & $4.27^{\mathrm{d}}$ & 0.29 & 14.76 \\
\hline 8 & Inger & $4.81^{\text {cd }}$ & 0.42 & 13.22 \\
\hline 9 & Tordis & $5.66^{\text {bd }}$ & 0.69 & 16.11 \\
\hline
\end{tabular}

length of annual growth was strongly influenced by the drought installed in July and August.

First three ranked genotypes obtained significant differences comparative with all others genotypes, without differentiation between them, while the last four genotypes ranking did not statistically differentiated between them. Under Northern Oltenia (Romania) conditions, where the rainfall regime is much higher and with lower temperatures during the vegetation period, annual growths recorded higher values to some of 


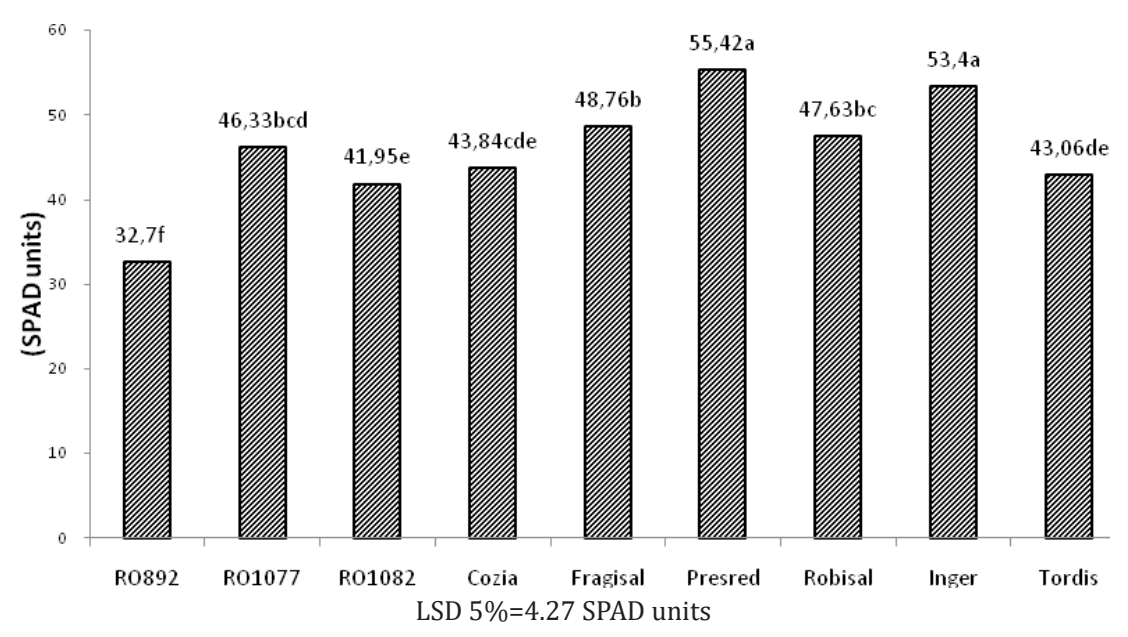

Figure 4. The content of chlorophyll

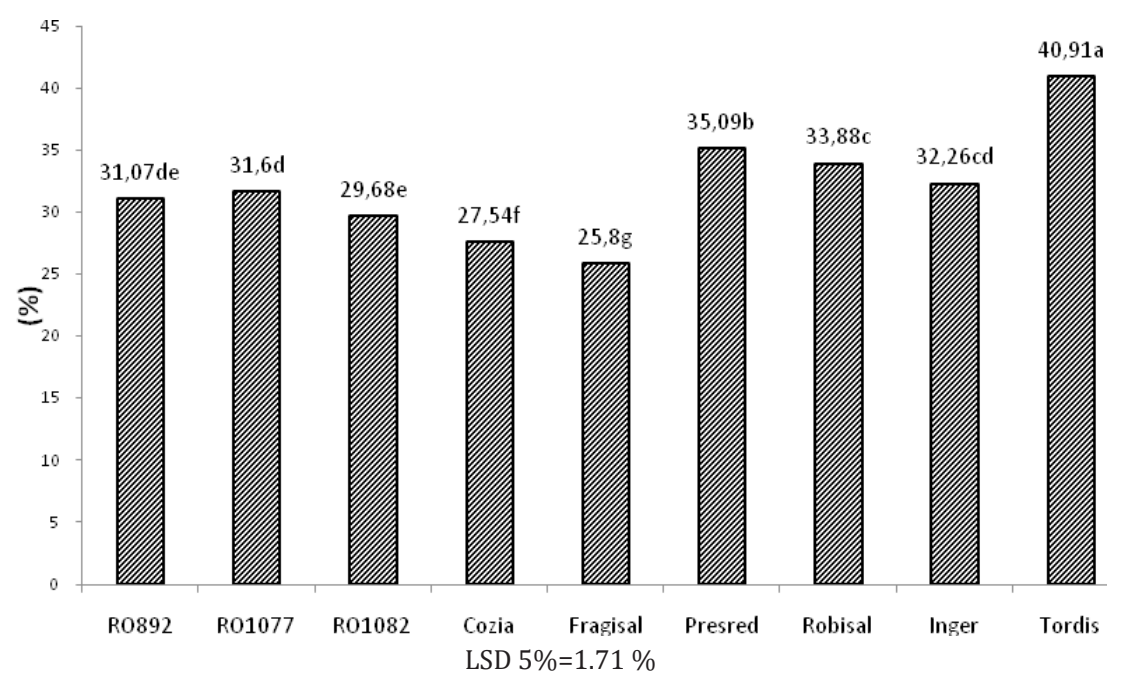

Figure 5. The content of soluble dry substance (\%)

the genotypes studied in this experiment (Botu et al., 2013).

Sprouting capacity is a parameter with genetic determinism but it is also expressed by the pedoclimatic conditions.

Concerning the number of shoots, it was recorded a variation amplitude of 4.2 shoots/pl. on Cozia (f), with a maximum on Robisal genotype (9.2 shoots/pl.) (a) (Fig. 3).

First classified genotype obtained significant differences compared with all others genotypes; while the last classified genotype recorded negative differences compared with all others genotypes, excepting the first over him.

An important element for yield estimation, based on destructive or non-destructive methods is the diameter at the bottom of shoot. The mean values of the diameter on the base of the stool at the end of growing season are presented in Table 2. Good results for the diameter on the base of the shoot were noticed for R0 1077 (8.21 mm) (a) and Pesred genotypes $(8.19 \mathrm{~mm})(\mathrm{a})$, which recorded significant differences. Lowest diameter values were observed for Robisal genotype $(4.27 \mathrm{~mm})$ (d).

Concerning of the chlorophyll content, the highest value was recorded by the Pesred genotype (55.42 SPAD units). First two classified genotypes obtained significant differences compare with all others genotypes. Also, the last two classified genotypes recorded significant differences compare with all others genotypes.

Concerning the water content, the highest value was obtained by Fragisal genotype (74.2\%) and the lowest by the Pesred genotype (64.91\%). First two classified genotypes obtained significant differences comparative with all others genotypes, those two being statistically differentiated between them. 
Also, the last two classified genotypes recorded significant differences comparative with all others genotypes, those two also being statistically differentiated between them.

High value of water content for Fragisal genotype it can be due because of the capacity to reduce water loss by reducing the level of stomata opening, fact that is proven by the low level of intensity of transpiration only for a short period and after that loss their leaves early in the drought but can quickly compensate for this loss with rapid re-sprouting facilitated by their higher hydraulic efficiency when the water condition return to normal (Savage et al., 2011).

Soare et al., 2016 said that photosynthesis intensity is correlated with photosynthetic active radiation, stomatal conductance and the amount of chlorophyll in a study made also in Southern Romania, but on other type of soil and almost same genotypes.

Production of bioenergy will become a priority, and energy crops for biomass, such as willow (like energy willow) is a perspective to be followed in the future. Results of Salix spp. genotypes showed their behaviour in the specific condition in Southern Romania and highlighted the differences in adaptation on sandy soils.

This study can provide indications for selection and zoning of best genotypes, so that willow culture can be a successful crop on sandy soils.

\section{Conclusions}

Obtained results for stem length and number of shoots/plant were strongly influenced by the lack of rainfall and high temperatures in July and August and because of that, they were much diminished. Pesred, Inger and RO 1077 genotypes registered higher annual growth of the stems.

As concern number of shoots, Robisal genotype registered higher values and also for diameter at the base of the shoot it was noticed RO 1077 and Pesred, which registered significant differences.

Energy willow can become an alternative for sandy land utilization, with the condition to provide and identify genotypes with more tolerance to specific conditions and a high percentage of grip.
Acknowledgement: This work presents the results of research obtained within the framework of the research project PN-II-PTPCCA-2013-4-2044, SAROSWE, No. 111/2014.

\section{References}

1. Bonosi L, Ghelardini L, Weih M (2010). Growth responses of 15 Salix genotypes to temporary water stress are different from the responses to permanent water shortage. Trees 24:843-854.

2. Botu I, Botu M, Preda S, Achim C, Lazăr A, Alecu A (2013). Comparative evaluation of Romanian and introduced Salix cultivar for short rotation coppice, South Western Journal of Horticulture, Biology and Environment, E-ISSN 20687958, IV(1): 35-42.

3. Dimitriou I, Baum C, Baum S, Busch G, Schulz U, Köhn J, Lamersdorf N, Leinweber P, Aronsson P, Weih M, Berndes G, Bolte A (2009). The impact of short rotation coppice (SRC) cultivation on the environment. LandbauforschungvTI Agriculture and Forestry Research (59): 159-162

4. Hernea C, Corneanu M, Sărac I, Petrescu I (2016). The behavior of willow commercial clones in the first growing season. A case study for three different sites from Banat area. Analele Universităţii din Craiova, seria Agricultură - Montanologie - Cadastru (Annals of the University of Craiova - Agriculture, Montanology, Cadastre Series), XLVI(2): 622-627.

5. Hernea C, Hollerbach W, Trava D, Corneanu M (2015). The Behaviour for SRC Willow Inger in Experimental Trial Ghilad, Romania. Bulletin UASVM Horticulture, 72(2), 376-380.

6. Karp A (2014). Willows as a source of renewable fuels and diverse products T. Fenning (Ed.), Challenges and opportunities for the World's forests, Springer Science+Business Media, Dordrecht: 617-641.

7. Rodzkin AI, Orlović SS, Krstić-Borivoj D, Pilipović AR (2015). The assessment of physiology parameters of willow plants as a criterion for selection of prospective clones, Зборник Матице српске за природне науке/ Matica Srpska J. Nat. Sci. № 129, 7-16;

8. Savage, J.A., Cavender-Bares, J.M., (2011). Contrasting drought survival strategies of sympatric willows (genus: Salix): consequences for coexistence and habitat specialization, Tree Physiology, 31(6)1: 604-614

9. Soare M, Nicolae I, Panita O, Soare R, Buse L (2016). Researches concernig the growing phisiology of some Salix $s p$. genotypes, 16th International Multidisciplinary Scientific GeoConference, 6(3): 333-340.

10. Weger J. Hutla, P, Bubeník J, (2016). Yield and fuel characteristics of willows tested for biomass production on agricultural soil. Res. Agr. Eng., 62: 155-161.

11. Wikberg J, Ögren E (2007). Variation in drought resistance, drought acclimation and water conservation in four willow cultivars used for biomass production. Tree Physiol 27:1339-1346. 